\title{
Sustainable Health Counselling Strategies for Reducing the Impact of Malnutrition Among Rural Children in Nigeria
}

\author{
Moses O. Ede ${ }^{1}$, Amanda U. Ugwoezuonu ${ }^{1}$, Chinwe C. Anowai ${ }^{2}$, Nneka Nwosu ${ }^{1}$, Nkechi Egenti ${ }^{1}$, \\ Ngozi C. Uzoagba ${ }^{3}$, Kelechi R. Ede ${ }^{4}$, Michael A. $\mathrm{Agu}^{5}$, Clara Ifelunni ${ }^{1}$ \& Emmanuel C. Okenyi ${ }^{1}$ \\ ${ }^{1}$ Department of Educational Foundations, Faculty of Education, University of Nigeria, Nsukka, P.M.B. 410001, \\ Enugu State, Nigeria \\ ${ }^{2}$ Department of Home Economic and Hospitality Management Education, University of Nigeria, Nsukka, Enugu \\ State, Nigeria \\ ${ }^{3}$ Medical Library, College of Medicine, University of Nigeria, Ituku Ozalla Enugu Campus, Nigeria \\ ${ }^{4}$ Department of Agricultural Science Education, Faculty of Education, Delta State University, Abraka, Delta State, \\ Nigeria \\ ${ }^{5}$ Department of Human Kinetics and Health Education, Faculty of Education, University of Nigeria, Nsukka, \\ Enugu State, Nigeria \\ Correspondrnce: Chinwe C. Anowai (P.hD), Department of Home Economic and Hospitality Management \\ Education, University of Nigeria, Nsukka. E-mail: chinwe.anowai@unn.edu.ng
}

Received: May 12, 2019 Accepted: June 15, 2019 Online Published: June 20, 2019

doi:10.5539/gjhs.v11n8p8 URL: https://doi.org/10.5539/gjhs.v11n8p8

\begin{abstract}
Objective: This study aimed to survey the sustainable health counselling strategies for reducing the impact of malnutrition among rural children in Nigeria.

Method: The population of the study comprised the entire 209 counsellors. Descriptive and inferential statistics were used to analyze the data collected.

Results: The result showed found that providing information about adequate food intake for sustainable health, awareness creation, and counselling, organizing conference on healthy nutrition, providing health awareness for sustainable growth; educating preschoolers' caregivers on fibre, knowledge of the best choice, knowledge of the sources of vitamin B12; assessing nutritional status of children; information on underweight to avoid obesity; and improving scope feeding behaviour through counselling are strategies that could reduce impacts of malnutrition among rural children in Nigeria. No significant was observed between male and female respondents with regards to sustainable health counselling strategies for reducing the impact of malnutrition among rural children.
\end{abstract}

Conclusion/Suggestion: Since eating practice of the rural children is poor and counselling strategies have been suggested, there is an urgent need for implementation of those strategies. Since evidence-based literature indicated that rural children in developing countries are at high risk of malnutrition and our findings showed strategies to reduce the proportion of children suffering from malnutrition, it implies that a Nutrition Rehabilitation Programme should be introduced to educate them on best nutritional practices.

Keywords: health counselling; malnutrition; food intake; rural children

\section{Introduction}

The importance of quality diet in overall growth and development of children at various ages seems to be a major concern of organizations, governments and the world at large. This has continued to be a major to practitioners in clinical psychology, health, and counselling. This is because of the perceived negative impacts of underfeeding on public health in most developing countries like Nigeria. Currently, the media has reported that over ten million children in Nigeria are experiencing severe malnutrition that could lead to mental deformation (Eno, 2017; Olawale, 2017). Prior to this report, the Nigeria Demographic and Health Survey (NDHS) (2013) decried the alarming prevalence of malnutrition which was at 29\%, (underweight) in children under five years old. Meanwhile, malnutrition in childhood could lead to many chronic diseases later in life. Malnutrition is most simply defined as nutrition imbalance (Dorland's Illustrated Medical Dictionary, 2011) that leads both underweight and overweight 
patients alike (White, Guenter, \& Jensen, 2012). According to Eze, Maduabum, Onyeke, Anyaegunam, Ayogu, Ezeanwu and Eseadi (2017), when foods are not consumed in quantities commensurate with individuals' body needs, malnutrition or over-nutrition may set in. Generally, malnutrition is described as either "undernutrition" or "overnutrition.

Previous study reported that over 50.6 million kids aged less than five years are half-starved in every developing country (Best et al., 2007). It was reported that a high percentage of children had poor eating behaviours (McNaughton et al., 2009) and only one-third and two-thirds of mothers indicated that their children consumed three or more dishes of vegetables and served of fruit per day respectively (World Health Organization, WHO, 2004). It is based on the same note that McNaughton et al., (2009) decried that despite government and organizations' efforts in providing guideline recommendations that reduced fat milk be introduced gradually from 2 years of age there is still a large proportion of children that consumed whole milk compared to low or reduced-fat milk. In Nigeria, for example, many children commonly consume high-energy, nutrient-poor foods that have a high quantity of cakes, doughnuts and sweet biscuits, and pies, pasties, and sausage rolls. These differences could be attributed to availability and accessibility in the area, however, further research is required to clarify this. McNaughton (2009) found that there were no significant differences between children living in urban and rural areas for intakes of vegetables, fruit or fried potato; however, children living in rural areas consumed non-fried potato more frequently. Evidence had shown that there is a high rate of malnutrition in this country (Quddus \& Bauer, 2013; WHO, 2004).

Rural children seem to remain a significantly understudied population and little is known about their healthy food consumption in rural areas in Nigeria. Literature showed that people living in rural areas consume a high quantity of vegetables, dairy fats and cooking oil (McLennan \& Podger, 1998). In this study area, there seems to be a high consumption of cassava, potato, garri, and yam among rural dwellers with little emphasis on protein related foods. Recent National Health Survey reported that rural population are associated with low fat or skim milk and possibly drink and eat carbohydrates frequently (Nigeria Demographic and Health Survey, NDHS, 2013). They were, however, more likely to consume the recommended number of serves of vegetables (Australian Institute of Health and Welfare, 2008).

These children are naturally vulnerable, often suffering from malnutrition with above $50 \%$ of them being moderate or severely malnourished (Rayhan \& Khan, 2006) which is a major risk factor for childhood mortality. Underweight and stunting appear to be a major problem among low-income children aged 2-10 years. It was revealed that an average child has low height-for-age, low weight-for-age and low weight-for-height which affect about $30 \%, 27 \%$ and $8 \%$ of the child population respectively (WHO, 2004).

Globally, nutritional status is considered as the best indicator of the well-being of young children and parents for monitoring the progress towards the millennium development goals (Rahman, Mostofa, \& Nasrin, 2009). The prevalence of malnutrition due to food insecurity is well recognised in the world, especially in developing countries. Hilly and forestry areas are the most vulnerable disadvantaged regions in Enugu State and which are inhabited by vast populations who are extremely poor. Children in this area suffer from food deficiency and malnutrition and these are serious problems in children under 10 years. In this area of this study, preschoolers are exposed and eat unhealthy foods.

In order to reduce malnutrition and food insecurity of children, there is a need for qualified and professional nutrition counsellors who will guide and counsel the rural mothers on dietary management for their sustainable health. Effective management of malnutrition requires collaboration among multiple interventions and disciplines such as counselling and other psycho-education. In many hospitals, malnutrition continues to be managed in silos, with knowledge and responsibility provided predominantly by the dietician. However, more holistic and interdisciplinary studies to tackle this significant issue are needed (Tappenden et al., 2013). Among these interdisciplinary process that can help to promote quality health care and healthy food intake is counselling.

Counselling is an integral part of guidance which provides the forum for interaction between a counsellor and counsellee (Nwoje, 2001). According to Uzoeshi (2004), counselling is a process of assisting a client to overcome problems and become happier and more effective individual in the environment. Operationally, counselling is defined as a helping relationship between counsellor and counsellees through which the counsellor helps both preschoolers and their caregiver to ensure adequate nutrition through awareness creation.

Nutrition Counsellors are primarily saddled with the responsibility of facilitating a total and holistic development of individuals who will be useful to themselves and society. Specifically, their roles according to Denga (2001) involves counselling, planning and developing of guidance programmes, appraising, interpreting and making appropriate referrals to relevant specialists on problems and issues that fall outside their competence orbit. Other 
roles of guidance counsellors include researching, evaluating and organizing programmes, attending conference and workshops, disseminating information for sustainable health and adequate nutrition awareness creation.

The goal of nutrition counselling is to ensure that there is increased awareness of the need for change, and reinforce commitment and continue new behaviours with regards to commensurable food intake (Stang \& Story, 2005). These can be achieved through creating a supportive climate for change and discuss personal aspects and health consequences of poor eating or sedentary behaviour, assess knowledge, attitudes, and beliefs as well as building on existing knowledge (Stang \& Story, 2005). This implies that nutrition counsellors provide health tips to people. However, despite the efforts of counsellors in both urban and rural areas, evidence abounds that poor nutrition is currently taking so many lives of children in rural areas in the Enugu state of Nigeria (Maduabum, 2015; Popkin, 2002).

It is worrisome that children at different ages are currently dying due to poor nutrient intake in rural areas in Enugu State (Eze, Maduabum, Onyeke, Anyaegunam, \& Eseadi, 2017; Maduabum, 2015). Despite the overwhelming importance of adequate nutrition to children's development and growth as well as power packed information delivery service system supported by nutrition counsellors, preschoolers are still dying geometrically. Children in Enugu State suffer from food deficiency and malnutrition (Eze, Maduabum, Onyeke, Anyaegunam, \& Eseadi, 2017). In this area of this study, preschoolers are exposed and eat unhealthy foods. It is against these disturbing concerns that the researchers aimed to explore sustainable health counselling strategies for reduction of malnutrition among rural preschoolers in Enugu State, Nigeria. In addition, we hypothesized that gender, age, and qualification are not indices for reduction of malnutrition among rural preschoolers in Enugu State, Nigeria. It is in view of this background that this study was carried out.

\section{Methods}

\subsection{Ethical Approval}

The ethical approval of the study was obtained from the Research Ethics Committee of the Faculty of Education, University of Nigeria, Nsukka. In addition, Enugu State Universal Basic Education Board and primary school headmasters/mistress gave approval for the current study in the study area.

\subsection{Population of the Study}

The population of the study comprised all the 209 professional and teacher counsellors in all 209 public primary schools in Obollo-Afor Education Zone of Enugu State.

\subsection{Participants}

The participants for the study were all the 209 teacher-counsellors in primary school. All participants were included in the study because all of them met the inclusion criteria. The inclusion criteria involve being ready to respond to the questionnaire, must be primary education staff, having knowledge of nutrition, health and counselling, and filling of an informed consent form.

\subsection{Design of the Study}

The study adopted a descriptive survey design. According to Nworgu (2006), a descriptive survey refers to those studies which aim at collecting data on, and describing in a systematic manner, the characteristics features or facts about a given population. This design was considered suitable for the study because it accorded the researchers the opportunity of collecting data from a sample considered to be representative of the population for describing systematically the sustainable health counselling strategies for reducing the impact of poor nutrition among children. The study was carried out in Obollo-Afor Education Zone of Enugu State Nigeria. The choice of this area of study is based on the observed increasing number of child mortality which appears to be as a result of malnutrition. The instrument for data collection in this study was a questionnaire developed by the researchers tagged: Sustainable Health Counselling and Malnutrition Scale (SHCMS). The instrument was developed from the review of previous literature on the knowledge of nutrition counsellors and sustainable health awareness roles for eliminating malnutrition (Eze, Maduabum, Onyeke, Anyaegunam, \& Eseadi, 2017; Maduabum, 2015; McNaughton, Dunstan, et al., 2009; Rahman, Mostofa, \& Nasrin, 2009; Rayhan \& Khan, 2006; Stang \& Story 2005). The instrument has both Section A and B. Section A focused on personal information of the respondents such as family income, place of residence, study field, academic level, marital status, age, and gender. Section B contained information on the knowledge of nutrition counsellors about sustainable health awareness roles for eliminating malnutrition put into 19 items. The items of the instrument had four-point response options of Strongly Agree (SA), Agree (A), Disagree (D) and Strongly Disagree (SD) which are weighted 4, 3, 2 and 1 respectively.

After the construction of the instrument, the questionnaire was validated by a panel of experts (three professional 
practising counsellors in University of Nigeria) and trial tested statistically (209 professional counsellors in primary schools from Anambra State of Nigeria) to determine the reliability of the instrument. The aim was to ascertain the accuracy and internal consistency of the questionnaire. From the suggestions, corrections, and feedback obtained, few items were rephrased to reduce bias, and the outline of the questionnaire was improved. Statistical analysis was done using Cronbach Alpha coefficient and the result gave Alpha Co-efficient value of 0.89 , hence indicated that the instrument is highly reliable to be used for the study.

Prior to the data collection, the researchers had obtained written informed consent from the Enugu State Director of Guidance and Counselling as well as Educational Foundations Research Committee to conduct the study. The researchers personally administered the copies of the questionnaire to the respondents $(\mathrm{N}=209)$. The administration of the questionnaire lasted for two months. The respondents who had Bachelor, Master and Doctoral degrees in psychology, Guidance and Counselling, Food Science and Nutrition and Home economics and hospitality management were allowed to participate during this survey. Among the researchers, two administered the instrument to counsellors in Igbo-Eze North and two in Igbo-Eze South while one researcher administered the instrument to counsellors in Udenu local government area, all in Obollo-Afor Education Zone of Enugu State. Some respondents who were not in the school during our several visits were contacted via their phone numbers and electronic mails. Each respondent was asked to tick or assign each health counselling strategy a score on each of the preselected criteria as indicated in the instrument.

Descriptive statistics were used to determine the mean of professional counsellors' responses with respect to sustainable health counselling strategies for reducing the impact of malnutrition. Mean score of 2.50 was purposively adopted as a benchmark for acceptance. That is an item that scores 2.50 and above was taken as agree and any mean score below 2.50 was taken as disagree. In addition, the t-test statistical tool was conducted at $95 \%$ significance level to ascertain the differences between male and female professional counsellors' responses. The inferential statistical tool (t-test) used to make a decision on the probability of difference observed between male and female counsellors are dependent on chance. Prior to that, the data were subjected to Shapiro-Wilks normality test to ensure adequate administration of the instrument according to gender and it gave Shapiro-Wilks normality value of 0.72 .

\section{Result}

Table 1. Socio-demographic characteristics of Participants

\begin{tabular}{llc}
\hline Variable & N (209) & $\%$ \\
\hline Family income & 96 & 200.64 \\
Less than 20,000 naira per month & 63 & 131.67 \\
$21,000-60,000$ naira per month & 45 & 94.05 \\
61,000 and above per month & & 154.66 \\
\hline Place of residence & 74 & 209 \\
Privately rented apartment & 100 & 73.15 \\
At home & 35 & 167.2 \\
Dorm & & 104.5 \\
\hline Study field & 80 & 114.95 \\
Psychology & 50 & 50.16 \\
Guidance and counselling & 55 & 24 \\
Food Science and Nutrition & 24 & 367.84 \\
Home economics and hospitality management & & 12 \\
\hline Academic level & 21 & 43.89 \\
Bachelor degree & & 25.08 \\
Master degree & & \\
\hline Doctoral degree & & \\
\hline
\end{tabular}




\begin{tabular}{lll}
\hline Marital status & & \\
Single & 57 & 119.13 \\
Married & 152 & 317.68 \\
\hline Gender & & \\
Male & 88 & 183.92 \\
Female & 121 & 252.89 \\
\hline Age & & \\
$25-35$ & 35 & 73.15 \\
$36-44$ & 56 & 117.04 \\
$45-55$ & 71 & 148.39 \\
$56-64$ & 47 & 98.23 \\
\hline
\end{tabular}

Table 1 showed that the participants were 88 males $(\mathrm{N}=183.92 \%)$ and 121 females $(\mathrm{N}=252.89 \%)$. The family income of professional counsellors were $200.64 \%$ Less than 20,000 naira per month $(\mathrm{N}=96), 131.67 \%$ for $21,000-60,000$ naira per month $(\mathrm{N}=63)$, and $94.05 \%$ for family with 61,000 naira and above per month $(\mathrm{N}=45)$. The responders' place of residence includes 74 participants privately rented apartment (154.66\%), 100 participants at home (209\%) and 35 participants in a dorm (73.15\%). For the field of study, 80 participants studied Psychology (167.2\%), 50 studied Guidance and Counselling (104.5\%), 55 Food Science and Nutrition (114.95\%), and 24 Home economics and hospitality management (50.16\%). Regarding academic level the respondents $176(367.84 \%)$ had Bachelor degree, 21(43.89\%) had a Master degree, and 12(25.08\%) had a Doctoral degree. Of those that responded, $57(119.13 \%)$ were single and $(317.68 \%)$ were married. The respondents age were within 25-35(73.15\%)35, 36-44 (117.04\%)56, 45-55 (148.39\%)71 and 56-64 (98.23\%)47.

Table 2. T-test analysis of sustainable health counselling strategies for reducing the impact of malnutrition

\begin{tabular}{|c|c|c|c|c|c|c|c|c|c|c|}
\hline \multirow{2}{*}{$\mathbf{S} / \mathbf{N}$} & \multirow{2}{*}{$\begin{array}{l}\text { Sustainable health counselling strategies } \\
\text { for reducing the impact of malnutrition }\end{array}$} & \multicolumn{9}{|c|}{$N=209($ Female $=109 ;$ Male $=100)$} \\
\hline & & Gender & $\bar{x}$ & SD & RMK & $\mathbf{F}$ & Sig & Df & $\mathbf{t}$ & Dec \\
\hline \multirow{2}{*}{1.} & \multirow{2}{*}{$\begin{array}{l}\text { Providing information on how to build on } \\
\text { existing knowledge about adequate food } \\
\text { intake for sustainable health }\end{array}$} & Female & 3.30 & .81 & \multirow{2}{*}{ A } & \multirow{2}{*}{2.139} & \multirow{2}{*}{.145} & \multirow{2}{*}{207} & \multirow{2}{*}{.145} & \multirow{2}{*}{ NS } \\
\hline & & Male & 3.28 & .75 & & & & & & \\
\hline \multirow{2}{*}{2.} & \multirow{2}{*}{$\begin{array}{l}\text { Creating awareness of foods that have more } \\
\text { calcium }\end{array}$} & Female & 3.38 & .735 & \multirow{2}{*}{ A } & \multirow{2}{*}{.096} & \multirow{2}{*}{.757} & \multirow{2}{*}{207} & \multirow{2}{*}{1.412} & \multirow{2}{*}{ NS } \\
\hline & & Male & 3.23 & .800 & & & & & & \\
\hline \multirow{2}{*}{3.} & \multirow{2}{*}{$\begin{array}{l}\text { Inviting international bodies (WHO) to } \\
\text { organize a conference on healthy nutrition } \\
\text { for rural citizens }\end{array}$} & Female & 3.37 & .84 & \multirow{2}{*}{ A } & \multirow{2}{*}{3.720} & \multirow{2}{*}{.055} & \multirow{2}{*}{207} & \multirow{2}{*}{1.769} & \multirow{2}{*}{ NS } \\
\hline & & Male & 3.14 & 1.04 & & & & & & \\
\hline \multirow{2}{*}{4.} & \multirow{2}{*}{$\begin{array}{l}\text { Providing health awareness for sustainable } \\
\text { growth }\end{array}$} & Female & 3.25 & .83 & \multirow{2}{*}{ A } & \multirow{2}{*}{.196} & \multirow{2}{*}{.658} & \multirow{2}{*}{207} & \multirow{2}{*}{-.464} & \multirow{2}{*}{ NS } \\
\hline & & Male & 3.30 & .81 & & & & & & \\
\hline \multirow{2}{*}{5 . } & Educating preschoolers' caregivers on the & Female & 3.30 & .85 & A & 328 & 567 & 207 & -325 & NS \\
\hline & health consequences of poor eating. & Male & 3.34 & .90 & & & & & - & \\
\hline 6 & Creating awareness of foods that have more & Female & 3.51 & .78 & $\mathrm{~A}$ & 011 & 015 & 207 & 15 & $\mathrm{~S}$ \\
\hline 0. & fibre & Male & 3.50 & .68 & 11 & .011 & (2) & 201 & .101 & 1 (N) \\
\hline 7 & Counselling students on the need for & Female & 3.41 & .70 & $\mathrm{~A}$ & 117 & 733 & 207 & 710 & S \\
\hline 1. & personal hygiene & Male & 3.33 & .74 & 11 & .117 & (1) & 201 & .110 & $10 \mathrm{~T}$ \\
\hline
\end{tabular}




\begin{tabular}{|c|c|c|c|c|c|c|c|c|c|c|}
\hline \multirow{2}{*}{8.} & \multirow{2}{*}{ wareness of hazards related to soft drinks } & Female & 3.26 & .84 & \multirow{2}{*}{ A } & \multirow{2}{*}{.892} & \multirow{2}{*}{.346} & \multirow{2}{*}{207} & \multirow{2}{*}{-.200} & \multirow{2}{*}{ NS } \\
\hline & & Male & 3.28 & .92 & & & & & & \\
\hline \multirow{2}{*}{9.} & \multirow{2}{*}{$\begin{array}{l}\text { Knowledge of the best choice to reduce the } \\
\text { amount of fat in the diet }\end{array}$} & Female & 3.28 & .805 & \multirow{2}{*}{ A } & \multirow{2}{*}{1.351} & \multirow{2}{*}{.246} & \multirow{2}{*}{207} & \multirow{2}{*}{-.127} & \multirow{2}{*}{ NS } \\
\hline & & Male & 3.29 & .74 & & & & & & \\
\hline \multirow{2}{*}{10.} & \multirow{2}{*}{ Knowledge of the sources of vitamin B12 and iron } & Female & 3.21 & .87 & \multirow{2}{*}{ A } & \multirow{2}{*}{.181} & \multirow{2}{*}{.671} & \multirow{2}{*}{207} & \multirow{2}{*}{-.233} & \multirow{2}{*}{ NS } \\
\hline & & Male & 3.24 & .91 & & & & & & \\
\hline \multirow{2}{*}{11.} & \multirow{2}{*}{ Knowing food that contains carbohydrates } & Female & 3.31 & .84 & \multirow{2}{*}{ A } & \multirow{2}{*}{.269} & \multirow{2}{*}{.605} & \multirow{2}{*}{207} & \multirow{2}{*}{-.242} & \multirow{2}{*}{ NS } \\
\hline & & Male & 3.33 & .90 & & & & & & \\
\hline 12 & $\mathrm{~A}$ & Female & 3.25 & .72 & $\mathrm{~A}$ & 750 & 385 & 207 & 75 & NS \\
\hline 12. & & Male & 3.21 & .78 & 11 & & .500 & 201 & & S \\
\hline 13 & In & Female & 3.41 & .67 & A & 0 & 768 & 207 & & NS \\
\hline & & Male & 3.47 & .71 & & & & & & \\
\hline 14 & & Female & 3.34 & .78 & $A$ & 2306 & 123 & 207 & 0 & NS \\
\hline 17. & tane & Male & 3.33 & .71 & $\pi$ & ס & $.12 J$ & 201 & t & No \\
\hline 15 & Nutrition counselling Intervention strategy to be & Female & 2.73 & .96 & A & 2462 & 118 & 207 & 35 & NS \\
\hline & targeted at preschooler & Male & 2.86 & .89 & 1. & & & & 1000 & \\
\hline 16 & A community intervention counselling for & Female & 2.87 & 1.17 & A & 0 & 13 & 7 & & NS \\
\hline & nutrition education. & Male & 2.83 & .01 & 11 & 0.210 & 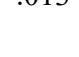 & 87 & & 100 \\
\hline 17 & Improving scope feeding behaviour through & Female & 3.23 & .86 & A & 002 & 961 & 207 & 9 & NS \\
\hline & counselling & Male & 3.11 & .91 & $n$ & .002 & 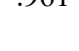 & 201 & .001 & No. \\
\hline 18 & Health counselling enlightenment campaign high & Female & 3.02 & .96 & 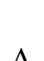 & 12 & 1 & 7 & & NS \\
\hline & nutritional status & Male & 3.18 & .72 & $\pi$ & 0.002 & .011 & 201 & -1.095 & IVI \\
\hline 1 & $\begin{array}{l}\text { Counselling to increase women education to make } \\
\text { them recentive to health interventions that will }\end{array}$ & Female & 3. & .77 & A & 787 & 6 & 207 & & \\
\hline & improve their nutritional status & Male & 3.22 & .88 & 12 & & & & & \\
\hline
\end{tabular}

Key: $\mathrm{N}=$ Number of respondents, $\bar{X}=$ mean, $\mathrm{SD}=$ Standard Deviation, $\mathrm{A}=$ Agree, $\mathrm{t}-\mathrm{cal}=\mathrm{t}$-test value calculated, $\mathrm{df}=$ degree of freedom, $\mathrm{Sig}=$ level of Significance, $\mathrm{Dec}=$ Decision.

The data in the Table 2 showed the sustainable health counselling strategies for reducing the impact of malnutrition among children. The result revealed that participants suggested providing information on how to build on existing knowledge about adequate food intake for sustainable health (Females $(F)=3.30 \pm .81$; Males $(M)=3.28 \pm .75$ ); creating awareness of foods that have more calcium $(F=3.38 \pm .735 ; \mathrm{M}=3.23 \pm .800)$; inviting international bodies (WHO) to organize conference on healthy nutrition for rural citizens $(F=3.37 \pm .84 ; \mathrm{M}=3.14 \pm .1 .04)$; providing health awareness for sustainable growth; educating school children caregivers on the health consequences of poor eating $(\mathrm{F}=3.25 \pm .83 ; \mathrm{M}=3.30 \pm .81)$; and creating awareness of foods that have more fiber $(F=3.51 \pm .78 ; \mathrm{M}=$ $3.50 \pm .68)$ as sustainable health counselling strategies. The results also showed that counselling students on the need for personal hygiene $(F=3.41 \pm .70 ; \mathrm{M}=3.33 \pm .74)$; awareness of hazards related to soft drinks $(F=3.26 \pm .84$; $\mathrm{M}=3.28 \pm .92)$; knowledge of the best choice to reduce the amount of fat in $\operatorname{diet}(F=3.28 \pm .804 ; \mathrm{M}=3.29 \pm .74)$; knowledge of the sources of vitamin $\mathrm{B} 12$ and iron $(F=3.21 \pm .87 ; \mathrm{M}=3.24 \pm .91)$; knowing food that contains carbohydrates $(F=3.31 \pm .84 ; \mathrm{M}=3.33 \pm .90)$; assessing nutritional status of children $(F=3.25 \pm .72 ; \mathrm{M}=3.21 \pm .78)$; information on Underweight to avoid Obesity $(F=3.41 \pm .67 ; \mathrm{M}=3.47 \pm .71)$; providing information on daily food intake $(F=3.34 \pm .78 ; \mathrm{M}=3.33 \pm .71)$; nutrition counselling intervention strategy to be targeted at preschoolers' mothers $(F=2.73 \pm .96 ; \mathrm{M}=2.86 \pm .89)$; a community intervention counselling for positive change in behaviour with regards to nutrition education $(F=2.87 \pm 1.17 ; \mathrm{M}=2.83 \pm .01)$; improving scope feeding behaviour through counselling $(F=3.23 \pm .86 ; \mathrm{M}=3.11 \pm .91)$; health counselling enlightenment campaign high parity of mothers which predisposes to poor nutritional status $(F=3.02 \pm .96 ; \mathrm{M}=3.18 \pm .72)$; counselling to increase women 
education to make them receptive to health interventions that will improve their nutritional status $(F=3.44 \pm .77$; $\mathrm{M}=3.22 \pm .88$ ) are sustainable health strategies for elimination malnutrition in Nigeria.

Furthermore, the results in Table 2 reveal no significant differences between male and female counsellors on the sustainable health counselling strategies for reducing the impact of malnutrition among preschoolers, given that the $P$-values for all t-tests ranged from $0-.127$ to 1.837 at 207 degrees of freedom and were, therefore, higher than the chosen level of significance (0.05). This suggests that both male and female counsellors in the target area agreed on the sustainable health counselling strategies for eliminating malnutrition among preschoolers regardless of gender.

\section{Discussion}

The results from present study suggest that providing information about adequate food intake for sustainable health, awareness creation and counselling, organizing conference on healthy nutrition, providing health awareness for sustainable growth; educating preschoolers' caregivers fibre, knowledge of the best choice to reduce the amount of fat in diet and carbohydrates, knowledge of the sources of vitamin B12; assessing nutritional status of children; information on underweight to avoid obesity; and improving scope feeding behaviour through counselling are strategies that could reduce impacts of malnutrition among rural children in Nigeria. Our finding corresponds with the finding of other studies from developing countries that showed the need for effective health services, regular home visits, supplementary feeding programmes for school children and an effective health education campaign on the importance of immunization and nutrition for rural people (Gibson et al., 2000; Ojofeitimi, 1984). This finding agreed with Quddus and Bauer (2013) who suggested that awareness, availability, and accessibility to family planning should be strengthened to limit the number of children in the family and increase female education including nutritional knowledge. It is interesting that nutritional counsellors are effectively updated in terms of their knowledge level. This will help nutrition campaign community health workers who would assist them in giving information on existing nutritional knowledge to rural dwellers. To ensure the implementation of the strategies, improved practices procedures, campaign team to promote quality health and nutrition messages, public media community-based to support micronutrient content in Nigerian basic schools are required (Dicken, Griffiths, \& Piwoz, 1997; Graciano, 1997; Smitasiri \& Dhanamitta, 1999).

In addition, the results revealed no significant differences between male and female counsellors on the sustainable health counselling strategies for reducing the impact of malnutrition among preschoolers. This suggests that both male and female counsellors in the target area agreed on the sustainable health counselling strategies for reducing the impact of malnutrition among preschoolers regardless of gender. Ibrahim, Wambiya, Aloka, and Raburu (2014) showed that awareness creation among secondary school students is not influenced by gender difference. This is to say that counsellors are discharging their professional roles especially as it concerns nutritive food intake among rural preschoolers (Zainuddin et al., 2013).

The implication of this finding is that if there is no policy intervention, those rural dwellers may record a high death rate. By implication, if awareness creations are not encouraged by nutritional counsellors and experts the dietary patterns of those preschoolers bare at stake. Meanwhile, caregivers ought to listen to possible awareness creation that may help in the reduction of malnutrition in rural locations. It implies that if efforts are not made in controlling the poor nutritional contents of food which those preschoolers consume, other chronic diseases may be attributed to that. In all, more research is required for improved practice, modification of dietary patterns of those in rural areas. It implies that a nutrition rehabilitation programme should be introduced to educate them on the best nutritional practices.

\section{Conclusion}

In many developing countries, children are apparently facing undernutrition and malnutrition. This has primarily continued to bring about ill-health, abnormal development, impairment of physical body, obesity, overweight and chronic disease among rural children. Such cases seem more prevalent in the rural location of Nigeria where schooling children population are vulnerable to diseases. It was the interest to seek a solution that this current study investigated the sustainable health counselling strategies for reducing the impact of poor nutrition among preschoolers. However, we found that providing information about adequate food intake for sustainable health, awareness creation and counselling, organizing conference on healthy nutrition, providing health awareness for sustainable growth; educating preschoolers' caregivers fiber, knowledge of the best choice to reduce the amount of fat in diet and carbohydrates, knowledge of the sources of vitamin B12; assessing nutritional status of children; information on underweight to avoid obesity; and improving scope feeding behaviour through counselling are strategies that could reduce impacts of malnutrition among rural children in Nigeria. On that note, mass media like television, radio, and newspapers should assist nutrition counsellors in disseminating nutrition information on the 
need to improve dietary diversification strategies.

\subsection{Limitations}

The researchers did not consider the ethnic groups of the participants therefore; further research could be done to fill the gap. The sample size appeared to be small which tends to affect the generalizability of the findings considering the number of counsellors in Nigeria. We, therefore, suggest that future studies may cover a larger population. In addition, the use of only one instrument also tends to affect the validity of the study.

\section{Funding}

The authors did not receive any financial support for the study.

\section{Competing Interests Statement}

The authors strongly declared no conflicts of interest with regards to the authorship, finance, and research.

\section{References}

Australian Institute of Health and Welfare. (2008). Rural, regional and remote health: Indicators of health status and determinants of health. Rural Health Series, 9, PHE 97. Canberra: Australian Institute of Health and Welfare.

Best, C. M., Sun, K., De-Pee, S., Bloem, M. W., Stallkamp, G., \& Semba R. D. (2007). Parental tobacco use is associated with increased risk of child malnutrition in Bangladesh. Nutrition, 23, 731-738. https://doi.org/10.1016/j.nut.2007.06.014

Denga, D. I. (2001). Counselling for entrepreneurship development at secondary school education level in Akwa Ibom state, Nigeria. The Counsellor, 22, 67-75.

Dicken, K., Griffiths, M., \& Piwoz, E. (1997). Designing by dialogue: a program planners' guide to consultative research for improving young child feeding. Washington, DC: Support for Analysis and Research in Africa.

Dorland's Illustrated Medical Dictionary. (2011). New York, NY: Elsevier Health Sciences.

Eno, M. (2017). Malnutrition rate alarming in parts of Nigeria-Group. Retrieved from https://www.premiumtimesng.com/news/more-news/231158-malnutrition-rate-alarming-in-parts-of-nigeriagroup.html

Eze, N. M., Maduabum, F. O., Onyeke, N. G., Anyaegunam, N. J., \& Eseadi, C. (2017). Awareness of food nutritive value and eating practices among Nigerian bank workers Implications for nutritional counselling and education. Medicine, 96, 10. https://doi.org/10.1097/MD.0000000000006283

Gibson, R. S., Hotz, C., Temple, L., Yeudall, F., Mtitimuni, B., \& Ferguson, E. (2000). Dietary strategies to combat deficiencies of iron, zinc, and vitamin A in developing countries: Development, implementation, monitoring, and evaluation. Food Nutr Bull, 21, 219-231. https://doi.org/10.1177/156482650002100218

Graciano, F. (1997). Localvita baseline survey results: South Sulawesi launch of SUVITAL (the social marketing campaign for the promotion of vitamin A-rich foods) in Ujung Pandang. Jakarta, Indonesia: Helen Keller International.

Ibrahim, R., Wambiya, P., Aloka, P. J. O., \& Raburu, P. (2014). The status of career awareness among selected Kenyan public secondary school students. Journal of Educational and Social Research, 4(6), 301-312. https://doi.org/10.5901/jesr.2014.v4n6p301

Maduabum, F. O. (2015). Nutritional awareness of bank workers in Lagos State, Nigeria (Master's thesis, Nsukka, Nigeria: University of Nigeria).

McLennan, W., \& Podger, A. (1998). National nutrition survey foods eaten, Australia, Canberra: Australian Government Publishing Service.

McNaughton, S. A., Dunstan, D. W., Ball, K., Shaw, J., \& Crawford, D. (2009). Dietary quality is associated with diabetes and cardio-metabolic risk factors. J Nutr., 139, 734-42. https://doi.org/10.3945/jn.108.096784

Nigeria Demographic and Health Survey (NDHS). (2013). The 2013 NDHS is the fifth demographic and health survey conducted in the country. Retrieved December, 2017, from https://dhsprogram.com/pubs/pdf/GF34/GF34.pdf

Nwoje, C. F. (2001). Guidance and counselling: A functional approach. Lagos: Joislad Enterprises.

Nworgu, B. G. (2006). Educational research: basic issues \& methodology (2nd ed.). Nsukka: University Trust 
Publishers.

Ojofeitimi, E. O. (1984). Assessment of the nutritional status of Nigerian rural children and mothers' perceptions of quality of life. Child Care Health Dev,10, 349-58. https://doi.org/10.1111/j.1365-2214.1984.tb00192.x

Olawale, G. (2017). Malnutrition: 10m Nigerian children risk mental deformity in adulthood. Rerieved from https:/www.vanguardngr.com/2017/08/malnutrition-10m-nigerian-children-risk-mental-deformity-adulthoo d/

Popkin, B. M. (2002). Understanding the nutrition transition: measuring rapid dietary changes in transitional countries. Public Health Nutrition, 5, 947-52. https://doi.org/10.1079/PHN2002370

Quddus, M. A. \& Bauer, S. (2013). Nutritional status of children associated with sociodemographic variables and food security in rural Bangladesh. Mal J Nutr, 19(2), 193-204.

Quddus, M. A., \& Bauer, S. (2013). Nutritional status of children associated with socio-demographic variables and food security in Rural Bangladesh. Malaysian Journal of Nutrition, 19,193-204.

Rahman, M., Mostofa, G., \& Nasrin, S. O. (2009). Nutritional status among children aged 24-59 months in rural Bangladesh: an assessment measured by BMI index. IJBA, 3, 1-7. https://doi.org/10.5580/aea

Rayhan, M. I., \& Khan, M. S. H. (2006). Factors causing malnutrition among under-five children in Bangladesh. PJN, 5, 558-562. https://doi.org/10.3923/pjn.2006.558.562

Smitasiri, S., \& Dhanamitta, S. (1999). Sustaining behavior change to enhance micronutrient status: Communityand women-based interventions in Thailand. Washington, DC: International Center for Research on Women. https://doi.org/10.1177/156482659902000211

Stang, J., \& Story, M. (2005). Guidelines for adolescent nutrition Services. Retrieved June, 2014, from http://www.epi.umn.edu/let/pubs/adol_book.shtm

Tappenden, K. A., Quatrara, B., Parkhurst, M. L, Malone, A. M., Fanjiang, G., \& Ziegler, T. R. (2013). Critical role of nutrition in improving quality of care: an interdisciplinary call to action to address adult hospital malnutrition. J Acad Nutr Diet., 113, 1219-1237. https://doi.org/10.1016/j.jand.2013.05.015

Uzoeshi, K. C. (2004). Guidance and counselling foundation and practice. Port Harcourt: Port-Harcourt Paragraphies

White, J. V., Guenter, P., Jensen, G., Malone, A., Schofield, M., Academy Malnutrition Work Group, A.S.P.E.N. Malnutrition Task Force, \& the A.S.P.E.N. Board of Directors. (2012). Consensus statement: Academy of nutrition and dietetics and American society for parenteral and enteral Nutrition: characteristics recommended for the identification and documentation of adult malnutrition (undernutrition). JPEN $J$ Parenter Enteral Nutr, 36, 275-83. https://doi.org/10.1177/0148607112440285

World Health Organization. (WHO). United Nations Children's Fund (UNICEF). (2004). The state of the World's children. WHO/UNICEF, New York.

Zainuddin, A. A., Selamat, R., Baharudin, A., et al. (2013) Nutritional status of Malaysian primary school children aged 8-10 Years: Findings from the 2008 National IDD Survey. Malaysian Journal of Nutrition, 19(2), $149-156$.

\section{Copyrights}

Copyright for this article is retained by the author(s), with first publication rights granted to the journal.

This is an open-access article distributed under the terms and conditions of the Creative Commons Attribution license (http://creativecommons.org/licenses/by/4.0/). 